\title{
SEASONAL AND ALTITUDIAL VARIATION IN FATTY ACID COMPOSITION OF NATIVE BEES
}

\author{
SuSMA GiRI $\diamond$ MichaEl E. Dillon $\uparrow$ DEPARTMENT OF ZOOLOGY AND PHYSIOLOGY \\ UNIVERSITY OF WYOMING — LARAMIE
}

\begin{abstract}
$\uparrow \quad$ ABSTRACT
Fatty acids (Fas), the most important energy resources in insects, may change in structure and thus function with changing temperature, a hypothesis termed 'homeoviscous adaptation'. We investigated whether the proportional composition of the most common fatty acids changes with seasonal (June to August) and altitudinal $(2060-3290 \mathrm{~m})$ variation in environmental temperature among four species of native bees. We identified the composition and proportion of each fatty acid using gas chromatography coupled with a flame ionization detector (GC-FID). Based on preliminary data, the most common fatty acids found in bees were palmitic acid (C 16:0), stearic acid (C 18:0), oleic acid (C 18:1), linoleic acid (C 18:2) and linolenic acid (C 18:3), with other fatty acids including myristic acid (C 14:0) and palmitoleic acid (C 16:1) also present in small amounts. We are currently 23eticulat GC data for larger bees and establishing protocols for fatty acid composition analysis of small tissue samples. Based on the seasonal and altitudinal variation in ambient temperature, we expect to see variation in fatty acid proportions in bees from different months at both sites.
\end{abstract}

\section{$\uparrow \quad$ INTRODUCTION}

Environmental temperature has profound effects on organisms and, in particular on ectotherms, which cannot regulate body temperature independent of environmental chamber. Changes in the temperature of their surroundings (and therefore body temperature) can thus strongly affect the physiology and survival of these organisms (Hazel and Williams 1990). Among various other effects, these thermal disturbances, by altering lipid properties, affect the performance of lipid related enzymes and proteins (Van Dooremalen, et al. 2011), and therefore can impact membrane structure and function (reviewed by Hazel 1995). These effects on lipids are particularly important because of the critical role lipids play as key energy storage molecules (fats), and as fundamental components of cell membranes (phospholipids and sterols).

Many ectotherms, including insects, store energy primarily as fat to sustain themselves during an annual quiescent phase (diapause, Hahn and Denlinger 2011) and the quantity as well as quality of fat stored strongly affects subsequent survival and fitness (e.g., Arrese and Soulages 2010). Aside from their importance in energy homeostasis, fatty acids (Fas) the components of lipids - are necessary for insect growth and morphogenesis, synthesis of pheromones, hormones, sex attractants, phospholipids and waxes, reproduction, and maintenance of colony hygiene. Further, lipids are the dominant components in cell membranes (Hazel and Williams 1990), which act as physical barriers between intra- and extra-cellular compartments, and govern molecular transport, ATPgeneration, cell signaling, and neural activity-the biochemical underpinnings of organism physiology. Therefore, in addition to the importance of fats for storage, they are critical for cell membrane function.

Changes in temperature can alter the function of fats, both as energy storage molecules and as key components of cell membranes. Whereas reduced temperatures compromise the mobilization of energy from stored fat and reduce the fluidity of phospholipid membranes (reviewed by Hochachka and Somero 2002), increased temperatures can lead to complete disruption of membranes through unintended breakages and fusions of lipids (Mariani et al. 1990; 
Hochachka and Somero, 2002). Such changes in fluidity can significantly alter cell membrane function with important physiological consequences. However, insects may take advantage of diversity in lipid types to regulate membrane properties and maintain membrane function in the face of changing temperatures (Hazel 1995), a hypothesis termed "homeoviscous adaptation" (Sinensky 1974).

The homeoviscous adaptation (HVA) hypothesis deals with the physical state of the membrane: its fluidity or lack thereof (Sinensky 1974). It posits that membranes function optimally only within a limited range of fluidity, that is the rate of movement of lipids in the lipid bilayer. HVA is therefore necessary to maintain fluidity and hence to preserve membrane integrity in low temperature conditions (Joanisse and Storey 1996).

Aside from its role in proper membrane function, membrane fluidity is also important in lipid metabolism as lipids can be metabolized only when they are fluid (Irving, et al. 1957).

Membrane fluidity depends primarily on the ratio of unsaturated to saturated fatty acyl chains in phospholipids (Ohtsu, et al. 1998). Fluidity is increased by increasing the degree of unsaturation. Whereas saturated fatty acids (SFAs, lack double bonds) yield more net energy but are less fluid at low temperatures, unsaturated (UFAs), in particular polyunsaturated fatty acids (PUFAs, 2 or more double bonds), stay liquid and therefore are more easily mobilized at lower temperatures but are more costly to produce and have a lower net energy yield. These considerations suggest that organisms in warm environments should favor SFAs (for their high net energy production) and organisms in cold environments should favor UFAs (to maintain lipid fluidity for both energy mobilization and membrane function; Linder 2000).

Although the ability to regulate FA composition to maintain membrane function in changing environmental temperatures should be particularly important for ectotherms, the HVA hypothesis has rarely been tested in terrestrial insects (Hahn and Denlinger 2011; but see Bennett, et al. 1997). The limited data available on insects and even more limited data available on seasonal and altitudinal variation in FA composition in insects make it unclear if the HVA hypothesis holds in these situations.

To address this limitation we are testing the 'HVA hypothesis' in native bees, which are small, largely ectothermic insects abundant throughout the growing season and across altitude. We collected bees monthly from June to August, 2012 from two altitudes in Grand Teton National Park (GTNP). We are currently determining fatty acid composition of these samples by GC analysis. These data will provide, to our knowledge, the first test of seasonal and altitudinal variation in fatty acid composition in bees.

\section{$\downarrow$ MeTHODS}

\section{Study area}

We collected bees from two sites along Death Canyon trail in GTNP (Figure 1): a low elevation site near Phelps Lake (2060 m asl N 43³0.220', W $\left.110^{\circ} 48.327^{\prime}\right)$, and a high elevation site near Static Peak (3290 m asl; N 43 40.799', W 110 49.096'). Both sampling sites were open meadows with abundant flowers supporting a diverse bee community.

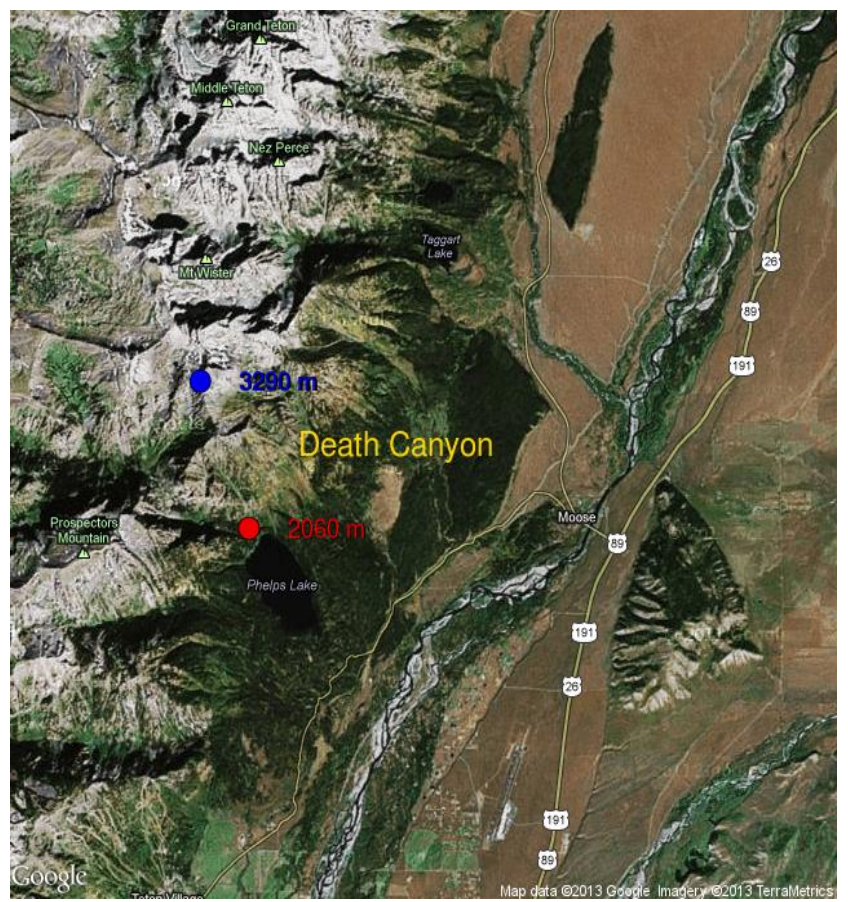

Figure 1. Bee collection sites within Grand Teton National Park. Point colors indicate low (red) and high (blue) elevation sites. 


\section{Bee collection and identification}

We collected bees by visual netting monthly from June to August at the low elevation site and in July and August at the high elevation site. We collected up to 10 individuals of each of the most common genera - Andrena, Bombus, Hylaeus, Lasioglossum, Megachile and Osmia. Bees were euthanized in cyanide within $30 \mathrm{~s}$ of capture and subsequently transported to the laboratory on ice. Within $24 \mathrm{~h}$ of capture, bee body mass was measured to $0.001 \mathrm{~g}$ (Acculab PP2060D) in the field and then re-measured to $0.0001 \mathrm{~g}$ (analytical balance, Acculab ALC-210.4, NY, USA) within eight days after returning to the lab. Bees were identified to genus and sub-genus (Michener et al.1994; Koch et al. 2012), and then stored at $-20{ }^{\circ} \mathrm{C}$ until used for analyses. Study was completed under permit GRTE-2012-SCI-0036 (Study \#: GRTE-00219).

\section{Characterizing the thermal environment}

We measured bee body temperature and environmental temperature throughout the season at both sites to determine temperature variability and calibrate expectations for changes in lipid physiology. We measured shaded air temperature $12 \mathrm{~cm}$ above the ground (roughly at flower height) every field day using a custom-made T-type thermocouple (4 mm long, $1 \mathrm{~mm}$ diameter) attached to a thermocouple reader (Omega HH23, TC-Omega, USA/Canada). The thermocouple was calibrated to a NIST-traceable thermocouple in a laboratory water bath $\left(0\right.$ to $\left.45^{\circ} \mathrm{C}\right)$.

Air temperature is not always a good predictor of animal body temperature because of micro-climatic variation in the determinants of heat balance (see Bakken 1992). We therefore measured bee body temperatures and "operative temperatures" (body temperatures when there is no metabolic heat production) for bees spanning the range of body sizes (from smallest to largest: Osmia, Colletes, Andrena, Megachile and Bombus). To minimize the effect of passive cooling, we inserted the thermocouple needle into the center of the bee thorax and read the body temperature within an average of $45 \mathrm{~s}$ of capture (range: 20-70 s). After subsequently euthanizing the bee in cyanide, we mounted it on a thermocouple and measured operative temperatures (shaded and unshaded at $12 \mathrm{~cm}$ above the ground; Figure 2).

\section{Fatty acid composition analysis}

We randomly selected a maximum of 10 individuals of each of the larger bee genera (Osmia,

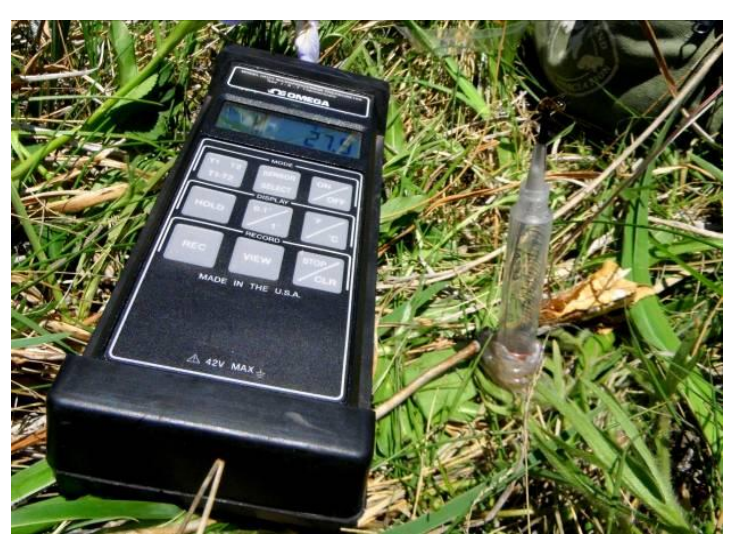

Figure 2. Operative temperatures were measured by inserting a fine thermocouple probe into a freshly killed bee.

Andrena, Megachile and Bombus) for fatty acid composition analysis. When fewer than 10 individuals of a genus were available, we included all individuals in the analysis. Because we were interested in internal lipid composition of the bees, we used a small paint brush, forceps and a laboratory air stream to remove any pollen attached to the bee cuticle, pile, or scopa. We then lyophilized the bee for $48 \mathrm{hrs}$ (Freezone 4.5, Labconco, Kansas city, USA), measured its dry weight and then homogenized it in $6 \mathrm{ml}$ methanol solution using tissuemizer (Tissuemizer, Tekmar, Cincinnati $\mathrm{OH})$. The homogenization was carried out in a $16 \mathrm{ml}$ test tube containing $1 \mathrm{mg}$ of internal standard (C 13:0; see Box 1). The fatty acids were then derivatized into fatty acid methyl esters (FAME) using methanolic $\mathrm{KOH}$ and prepared for GC analysis as described by Murrieta, et al (2003). We separated FAME using a Hewlett-Packard 6890N, equipped with flame ionization detector and a $60 \mathrm{~m} \mathrm{X} 0.25 \mathrm{~mm}$ fused silica capillary column $(0.25 \mu \mathrm{m}$ film thickness $)$. Oven temperature was maintained at $75^{\circ} \mathrm{C}$ for $1 \mathrm{~min}$ and then increased to $170{ }^{\circ} \mathrm{C}$ at the rate of $6.5^{\circ} \mathrm{C} / \mathrm{min}$. The oven temperature was held at $170{ }^{\circ} \mathrm{C}$ for $27 \mathrm{~min}$, then increased to $215^{\circ} \mathrm{C}$ at $10^{\circ} \mathrm{C} / \mathrm{min}$ and held for $30 \mathrm{~min}$. Finally, the temperature was raised to $230{ }^{\circ} \mathrm{C}$ at 40 ${ }^{\circ} \mathrm{C} / \mathrm{min}$ and held for $3 \mathrm{~min}$. Hydrogen from purified air was used as the carrier gas with a split ratio of 50:1 and a split flow of $35.5 \mathrm{ml} / \mathrm{min}$. We will identify fatty acids by comparing retention times with fatty acid methyl ester (FAME) standards.

\section{$\downarrow \quad$ RESULTS AND DISCUSSION}

We collected a total of 80 bees from 10 genera at the high elevation site $(3290 \mathrm{~m})$ and 169 individuals from 19 genera at the low elevation site (2060 m; Table 1).

Hylaeus and Osmia were common 
throughout the season at both high and low elevations. Lasioglossum was common at $3290 \mathrm{~m}$, but rare at 2060 $\mathrm{m}$. We might have missed the peak season for Lasioglossum at $2060 \mathrm{~m}$ leading to sampling of fewer individuals of the genus. Though seasonally variable, Heriades and Megachile were common at $2060 \mathrm{~m}$ but less so at $3290 \mathrm{~m}$. Seasonal and altitudinal variation in genus abundance limited the number of genera that could be included in altitudinal (Table 2) and seasonal (Figure 4) comparisons of lipid physiology.

\section{Seasonal and altitudinal variation in temperature}

As expected, air temperature was higher throughout the season at the low elevation site (2060 m) compared to the high elevation site (3290 m; Figure 5). We therefore expect strong differences in fat physiology across elevation. Similarly, although the seasonal trend in air temperature was different across the sites, ambient temperature varied widely across the season. We thus expect to see differences in lipid physiology across the season at each site (see specific predictions below).

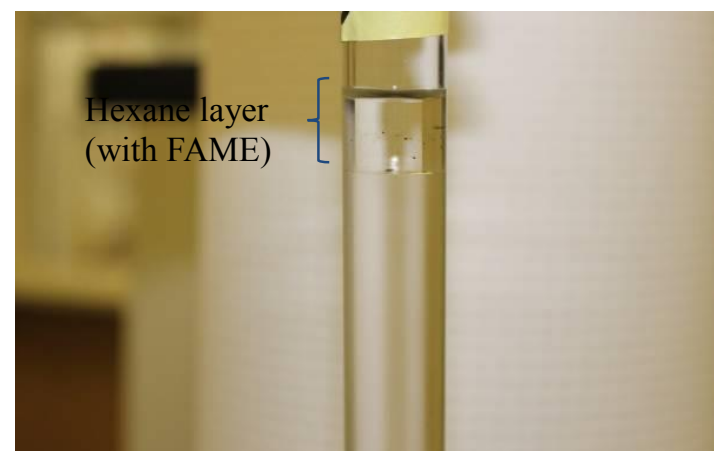

Figure 3. Separation of FAME from bee tissue.

Table 1. Total bees collected from two GTNP sites throughout the season

Box 1. Preparation of sample tubes with internal standard (IS)

Wash $16 \mathrm{ml}$ clean glass tubes with hexane to remove any organic solvent/lipid and dry the tubes

Weigh each tube with caps on

Add $1 \mathrm{ml}$ of $1 \mathrm{mg} / \mathrm{ml}$ of IS (C 13:0) in chloroform

Reweigh the tubes with respective caps on

Unscrew the caps and leave the tubes in hood to evaporate the chloroform (it takes $\sim 28-36 \mathrm{hrs}$ ).

Store the tubes with caps on, at $-20^{\circ} \mathrm{C}$ until used.

\begin{tabular}{|c|c|c|c|c|c|c|}
\hline \multirow[t]{2}{*}{ Genus } & \multicolumn{2}{|l|}{ June } & \multicolumn{2}{|l|}{ July } & \multicolumn{2}{|l|}{ August } \\
\hline & $2060 \mathrm{~m}$ & $3290 \mathrm{~m}$ & $2060 \mathrm{~m}$ & $3290 \mathrm{~m}$ & $2060 \mathrm{~m}$ & $3290 \mathrm{~m}$ \\
\hline Andrena & 10 & & 7 & 2 & 1 & 2 \\
\hline Epeolus & & & & & & 1 \\
\hline Halictus & 4 & & 1 & & & \\
\hline Hoplitis & & & 6 & 3 & 1 & 3 \\
\hline Hylaeus & & & 4 & 4 & 9 & 11 \\
\hline Lasioglossum & 11 & & 3 & 5 & 1 & 13 \\
\hline Megachile & & & 5 & 2 & 15 & 2 \\
\hline Osmia & 10 & & 11 & 13 & 6 & 9 \\
\hline Ashmeadiella & & & 3 & & 1 & \\
\hline Colletes & & & & 1 & 2 & 1 \\
\hline Heriades & & & 3 & & 10 & \\
\hline Sphecodes & & & & & 1 & \\
\hline Bombus & 10 & & 7 & 6 & 13 & 2 \\
\hline Anthophora & & & 3 & & 3 & \\
\hline Ceratina & & & 2 & & & \\
\hline Chelostosoma & & & 1 & & & \\
\hline Dufourea & & & 1 & & & \\
\hline Perdita & & & 2 & & & \\
\hline Protosmia & & & 1 & & & \\
\hline Stelis & & & 1 & & & \\
\hline
\end{tabular}




\section{Seasonal and altitudinal variation in total water content}

So far, total water content has been measured for three bee genera: Andrena, Megachile and Osmia. We will be measuring the same for other genera in future. For Andrena, Megachile and Osmia, the total water content decreased from June/July to August.

Table 2. Sample sizes of bee genera with sufficient sampling at the two sites (2060 m and $3290 \mathrm{~m}$ ) to allow for analysis of altitudinal variation in FA composition.

\begin{tabular}{|llll|}
\hline Genus & Month & $\mathbf{2 0 6 0} \mathbf{~ m}$ & $\mathbf{3 2 9 0} \mathbf{~ m}$ \\
Bombus & July & 7 & 6 \\
Hylaeus & July & 4 & 4 \\
& August & 9 & 11 \\
Osmia & July & 11 & 13 \\
& August & 6 & 9 \\
\hline
\end{tabular}

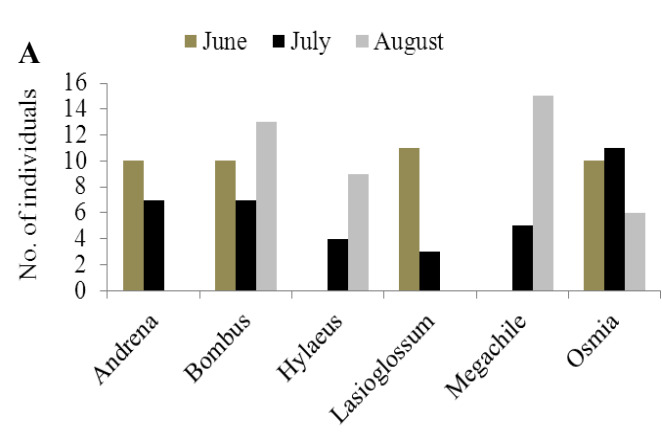

Bee genera

B Bee genera $\quad$ July $\quad$ August

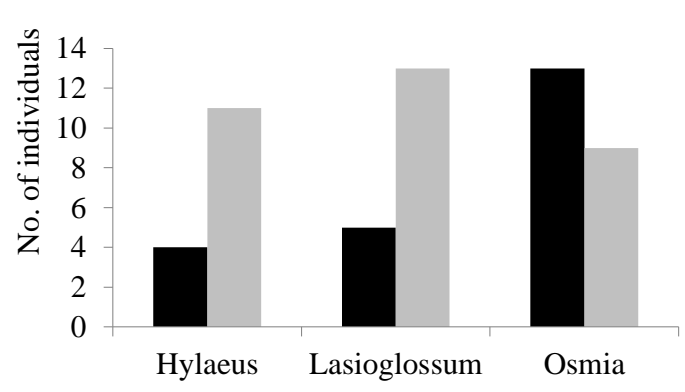

Figure 4. Bees with sufficient sampling across the season to allow for analysis of seasonal variation in FA composition at $2060 \mathrm{~m}$ (June to August) (A) and 3290 m (July and August) (A).

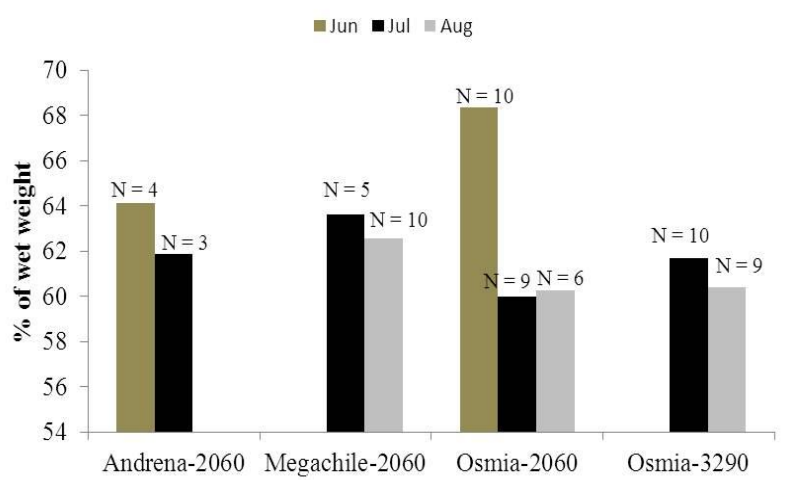

Figure 5. Seasonal variation in total body water content of Andrena, Megachile and Osmia at low elevations site and Osmia at high elevation site.

\section{Seasonal and altitudinal variation in temperatures}

As expected, air temperature was higher throughout the season at the low elevation site (2060 $\mathrm{m}$; Figure 6) compared to the high elevation site (3290 $\mathrm{m}$, Figure 6). We therefore expect strong differences in fat physiology across elevation. Similarly, although the seasonal trend in air temperature was different across the sites, ambient temperature varied widely across the season. We thus expect to see differences in lipid physiology across the season at each site (see specific predictions below)

\section{Preliminary GC data}

Preliminary analyses suggest that the most common fatty acids found in native bees are palmitic acid (C 16:0), stearic acid (C 18:0), oleic acid (C 18:1), linoleic acid (C 18:2) and linolenic acid (C 18:3). In standard fatty acid nomenclature, the value to the left of the colon refers to the number of carbons in a FA and the value to the right of the colon refers to the number of unsaturated bonds in the FA. We therefore included these five FAs in the FAME standard (Figure 7). As we didn't detect the presence of tridecylic acid (C13:0) in bees, we used this fatty acid as our internal standard. Many other fatty acids including myristic acid (C 14:0) and palmitoleic acid (C 16:1) are also present at low levels in bees.

By comparing the retention times of fatty acids from bee samples with the chromatogram for the FAME standards (Figure 7), we were able to identify fatty acids in Bombus impatiens (Figure 8). We will use this approach to identify FA profiles in the remaining samples. 


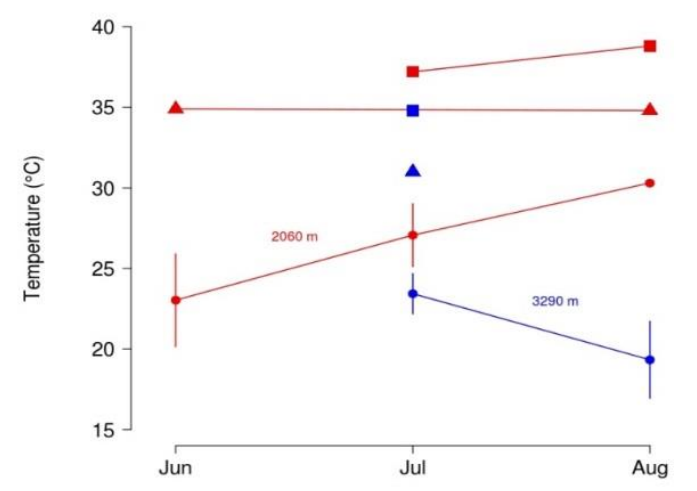

Figure 6. Seasonal variation in ambient temperature at 2060 $\mathrm{m}$ (red circles and line) and at $3290 \mathrm{~m}$ (blue circles and line). Triangles and squares are body temperature of Bombus and Megachile, respectively, at low (red) and high (blue) elevations.

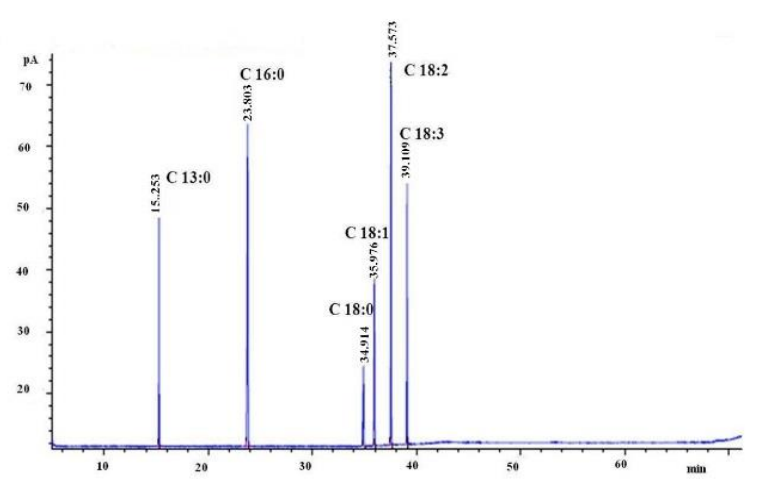

Figure 7. GC-FID chromatogram showing six standard FAMEs. The rotated number above each peak gives the retention time in minutes and the text denotes the type of fatty acid represented by the peak.

Figure 8. GC-FID chromatogram showing fatty acids

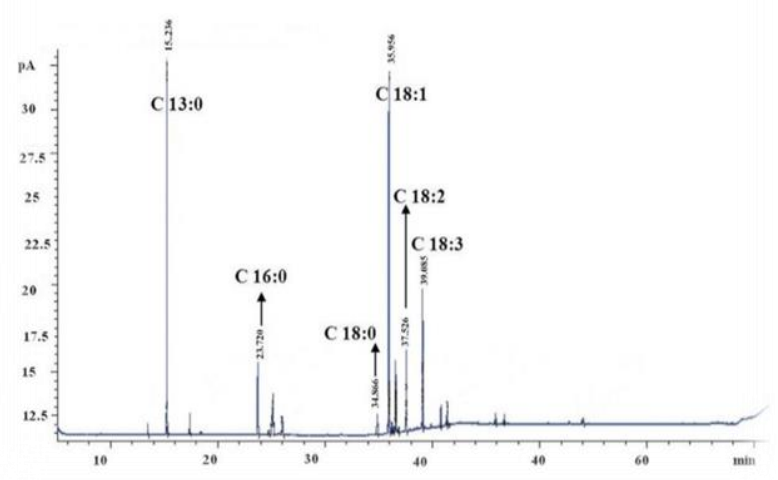

present in a bumblebee (B. impatiens). We identified the fatty acids by comparing the retention time with the standards. Labels as in Figure 7.

\section{PROJECT PROGRESS AND PLAND FOR COMPLETION}

The summer field work yielded excellent seasonal and altitudinal sampling of a diverse group of native bees (Table 1). In the lab, we have validated the derivatization approach for native bees, including optimizing the FAME preparation technique, and generating standard peaks for determination of fatty acid profiles (Figure 7). We are now in the process of analyzing GC data to determine the fatty acid composition of each bee by comparison with FAME standards and plan to complete data analysis by May 2013. Additionally, we have collected pollen from bee scopa and if possible for such small samples, will determine FA composition of these samples for comparison with results for bees. These data will allow us to test several predictions:

\section{Prediction 1: Endothermic bumblebees will have lower and invariant PUFA: SFA ratios.}

Bumblebees maintain a constant body temperature even when ambient temperature varies widely (Figure 6). They can regulate high body temperatures independent of environmental temperature both during foraging trips and while in the hive (Heinrich 1974). Because bumblebees maintain high body temperatures independent of season and altitude, we predict they will have low PUFA: SFA ratios relative to other bees and that PUFA: SFA ratios won't vary with season or altitude in bumblebees.

\section{Prediction 2: PUFA: SFA ratios will be higher for the bees collected in early spring and late fall.}

The cool temperatures of early spring and late fall (Figure 6) may require higher PUFA: SFA ratios. Further, bees emerging from diapause are likely to still have diapause fatty acid signatures and those preparing for diapause are likely to begin accumulating PUFA's in their fat bodies (Hahn and Denlinger 2011).

\section{Prediction 3: High altitude bees will have higher PUFA: SFA ratios.}

Lower temperatures at higher elevations (Figure 6) will likely require higher PUFA: SFA ratios to maintain membrane function. We predict that, within-species, bees collected from higher altitudes will have higher PUFA: SFA ratios. Our collections will allow us to compare FA composition across altitude for 3 genera in July, and 2 genera in August (Table 2).

Prediction 4: Shifts in PUFA: SFA ratios will be driven by endogenous lipid physiology not by diet. 
Diet can strongly influence fatty acid composition in body tissues and even propensity for entering diapause (Ruf and Arnold 2008). However, tissue fatty acid composition can change even when diet is the same (Khani et al. 2007). Bees acquire dietary lipids only from the pollen they eat. Pollen can contain from 1-18\% lipid by mass (Roulston and Cane 2000), but pollen lipid content has not been found to change systematically with any measured environmental or ecological factor (Roulston et al., 2000). We therefore predict little seasonal or altitudinal variation in pollen lipid content or quality (PUFA: SFA), such that changes in bee PUFA: SFA ratios are driven by endogenous shifts in lipid physiology.

\section{$\downarrow$ ACKNOWLEDGEMENTS}

We would like to thank the UW-NPS Research Center for supporting this study. We thank Dr. Daniel C. Rule (Professor, Dept. of Animal Science) for his valuable suggestions, equipment use and help with the GC methodology and data analysis. We also thank Emily Melson (Rule lab) for her help with GC analyses, and members of the Dillon lab, Basant Giri and Sagun Khadka for help with field work and bee identification.

\section{$\downarrow \quad$ Literature CiTED}

Arrese EL, Soulages JL. 2010. Insect fat body: energy, metabolism, and regulation. Annual Review of Entomology 55:207-225.

Bakken GS. 1992. Measurement and Application of Operative and Standard Operative Temperatures in Ecology. American Zoologist 32:194-216.

Bennett VA, Pruitt NL, Lee Jr., RE. 1997. Seasonal changes in fatty acid composition associated with cold-hardening in third instar larvae of Eurosta solidaginis. Journal of Comparative Physiology B: Biochemical, Systemic, and Environmental Physiology 167:249-255.

Van Dooremalen C, Suring W, Ellers J. 2011. Fatty acid composition and extreme temperature tolerance following exposure to fluctuating temperatures in a soil arthropod. Journal of Insect Physiology 57:1267-1273.

Hahn DA, Denlinger DL. 2011. Energetics of Insect Diapause. Annual Review of Entomology
56:103-121.

Hazel JR. 1995. Thermal Adaptation in Biological Membranes: Is Homeoviscous Adaptation the Explanation? Annual Review of Physiology 57:19-42.

Hazel JR, Williams E. 1990. The role of alterations in membrane lipid composition in enabling physiological adaptation of organisms to their physical environment. Progress in Lipid Research. 29:167-227.

Heinrich B. 1974. Thermoregulation in bumblebees. Journal of Comparative Physiology A: Neuroethology, Sensory, Neural, and Behavioral Physiology 88:129-140.

Hochachka PW, Somero GN. 2002. Biochemical Adaptation: Mechanism and Process in Physiological Evolution. Oxford University Press, USA.

Irving L, Schmidt-Nielsen K, Abrahamsen NSB. 1957. On the Melting Points of Animal Fats in Cold Climates. Physiological Zoology 30:93-105.

Joanisse DR, Storey KB. 1996. Fatty acid content and enzymes of fatty acid metabolism in overwintering cold-hardy gall insects. Physiological Zoology 69:1079-1095.

Khani A, Meharramipour S, Barzegar M. 2007. Cold toleracetrehalose accumalition in overwintering larvae of the codling moth Cydia Pomonella (hepidoptera Tertricidae). European Jornal of entomology. 104: 385392.

Koch J, Strange J, Williams P. 2012. Bumble bees of the western United States. USDA Forest Service Research Notes.

Linder CR. 2000. Adaptive Evolution of Seed Oils in Plants: Accounting for the Biogeographic Distribution of Saturated and Unsaturated Fatty Acids in Seed Oils. The American Naturalist 156:442-458.

Mariani P, Rivas E, Luzzati V, Delacroix H. 1990. Polymorphism of a lipid extract from Pseudomonas fluorescens: structure analysis of a hexagonal phase and of a novel cubic phase of extinction symbol Fd-. Biochemistry 29:6799-6810.

Michener CD, McGinley RJ, Danforth BN. 1994. The 
bee genera of North and Central America (Hymenoptera: Apoidea). Smithsonian Institution Press.

Murrieta CM, Hess BW, Rule DC. 2003. Comparison of acidic and alkaline catalysts for preparation of fatty acid methyl esters from ovine muscle with emphasis on conjugated linoleic acid. Meat Science 65:523-529.

Ohtsu T, Kimura MT, Katagiri C. 1998. How Drosophila species acquire cold tolerance. European Journal of Biochemistry 252:608 611.

Roulston TH, Cane JH. 2000. Pollen nutritional content and digestibility for animals. Plant systematics and evolution. 222: 187-209.

Roulston TH, Cane JH, Buchmann SL. 2000. What governs protein content of pollen: pollinator preferences, pollen-pistil interactions, or phylogeny? Ecological Monographs 70:617643.

Ruf T. Arnold W. 2008. Effects of unsaturated fatty acids on hibernation and torpot: a review and hypothesis American Journal of PhysiologyRegulatory, Intergrative and comparative physiology. 294: R1044-R1052.

Sinensky M. 1974. Homeoviscous adaptation-a homeostatic process that regulates the viscosity of membrane lipids in Escherichia coli. Proceedings of the National Academy of Sciences 71:522. 